\title{
Experiences of Turkish Cypriot, Kurdish and Turkish Youth in Creating Transnational Social Spaces in London Schools
}

\author{
Dogus SIMSEK ${ }^{*}$ Regent's University London, $U K$ \\ Border Crossing: Transnational Working Papers, No. 1302 \\ www.tplondon.com/journal/index.php/bc/
}

2013

\begin{abstract}
This paper focuses on the role of school in identity formation of Turkish Cypriot, Kurdish and Turkish youths (thereafter TCKT) living in London and explores the perceptions of young people about their school life, mainly focusing on secondary school experiences, and exploring the difficulties faced in their relations with peers. It also examines the forms of homogeneity and heterogeneity within the school environment, examining their influence on identity formation and the negotiation of transnational social spaces by TCKT youth. The homogeneity of schools in London prevents them from forming identities based on interaction with various cultures and, therefore, limits their ability to create transnational social spaces.
\end{abstract}

Keywords: School, Turkish Cypriot, Kurdish and Turkish youth, Transnational Social Space, Identity, London

SUGGESTED CITATION:

Simsek, Dogus (2013) 'Experiences of Turkish Cypriot, Kurdish and Turkish Youth in Creating Transnational Social Spaces in London Schools'. Border Crossing: Transnational Working Papers, No. 1302. Available at:

www.tplondon.com/journal/index.php/bc/

* Dr Dogus Simsek is member of Regent's Centre for Transnational Studies at Regent's University London, Inner Circle, Regent's Park, London, NW1 4NS, United Kingdom. E-mail: simsekd@regents.ac.uk 


\section{Introduction}

This paper focuses on the experiences of Turkish Cypriot, Kurdish and Turkish youth (thereafter 'TCKT') living in London in the school environment and the challenges faced by young people with a transnational background. It explores the ways the school experiences of young people influence their identity formation in a transnational social space ${ }^{1}$. Identity formation of TCKT youth will be analysed in relation to individual, social, and structural factors. The influence of school on identity formation represents a structural factor. I aim to show in which ways school environment play a crucial role in the construction of transnational social space (TSS) and identity. I argue that school environment plays a crucial role for social mobility if it mixes such diverse identifications as a whole in its context. It therefore questions the levels of 'multiculturality' in the school environment by focusing on the experiences of TCKT youth at school.

School life is a crucial part of the everyday life of young people. School represents a place where young people socialise with peers from different ethnic and national backgrounds and a place where they negotiate their participation in the receiving society and in defining themselves (Kivisto, 2003; Levitt and Waters, 2002; Portes and Rumbaut, 2001a). Theoretical literature on education and second generation migrants focuses on school choice and racial differentiation within schools (Kasinitz et al., 2008; Sikkink and Emerson, 2008), relating to the success, achievement, and failure of young people (Enneli et al., 2005; Johnson et al., 2010; Portes and Rumbaut, 2001), and on parental involvement in education (Coleman, 1988; Zhou and Bankston, 1994). The majority of the literature highlights the educational successes and failures of migrant children. Much of the literature on migration and education attempts to describe, explain, and analyse the way migrant children are incorporated into the education system (Tomlinson, 1983).

The school environment in Britain is multicultural and multiracial (Berdichevsky, 2008; Giles and Taylor, 1977; Patterson, 1969; Taylor, 1974) and migrants send their children to schools and universities in multiethnic neighbourhoods (Kivisto, 2003). According to Levitt and Waters (2002), this situation creates pressure to identify racially in the case of black Americans. These identifications are seen as an outcome of the relationship with peers from different ethnic backgrounds. Anthias (2002) notes that Greek-Cypriot and Asian youths experience a sense of isolation from English youths. This isolation is related to 'feeling other' and racist rejection. Anthias focuses on direct expressions of racism in the case of studied groups in a school environment. Back (1996) also stresses the experiences of racism among minority youths in multicultural environment. Enneli et al., (2005) argue that young Turkish Cypriots, Kurds and Turks are disadvantaged groups in London and they relate this disadvantage to ethnicity and class. Unlike Enneli et al. (2005), Portes and Rumbaut (2001) argue that minority groups can be successful when they form strong ethnic ties in the school environment.

In order to explore the role of school in constructing TSS and identity, this paper focuses on the school environment itself and the interactions taking place with members of the same or different ethnic backgrounds. Social interactions are analysed in a transnational social space, which includes sharing experiences developed by practicing culture and experiencing a social life across the borders of nation-states. The paper also explores the perceptions of young people about their school life, mainly focusing on secondary school experiences, and exploring the difficulties faced in their relations with peers. By exploring the structure of schools in London and their influence on the identity formation of young people and transnational social spaces, this paper will distinguish the specific role play by homogeneous and heterogeneous environments at school.

The research was conducted in North London. I carried out unstructured interviews with forty-five mixed gender Turkish Cypriots, Kurdish and Turkish youth (between the ages of 18-23 years old) to find out the role of school in the identity formation of TCKT youth.

\footnotetext{
${ }^{1}$ The concept of 'Transnational social space' is being defined as a metaphorical space where individual identity is negotiated, and is composed of experiences, ties, interactions, representation, links and material artefacts.
} 


\section{The Role of the School Environment in Forming Identities}

The education of minority groups in Britain has moved from assimilationist model to a cultural pluralist model which theoretically allows minority groups to maintain their own cultures, languages, traditions and religions (Bolton, 1979). According to Tomlinson, 'there was initially no central policy or planning to meet the needs of immigrant children in the education system in 1960s' (1983: 16). Previously, the major concern of the education system was to culturally assimilate immigrant children into 'British life' (Tomlinson, 1983). This model caused a lack of identification with the school and poor school achievement of children with a migrant background, because issues such as different learning processes and lack of fluency in English were not considered. In the 1970s, the education system and school policy started to pay more attention to the needs of ethnic minority communities in retaining their linguistic and cultural traditions (Tomlinson, 1983). In 1981, it became a duty for schools to take into consideration, in policy and practice, ethnic minorities' needs such as language courses and cultural activities. This allowed migrants to register in any school (Little and Willey, 1981).

Despite some recognition by the educational system, ethnic minority children continued to be a part of a wider group of 'disadvantaged' children according to many authors (Enneli et al., 2005; Mehmet Ali, 2001; Tomlinson, 1983). This might be explained by the organisation of schools. TCKT youth mainly attend neighbourhood state schools close to their homes. In London, these schools are situated in Haringey, Islington and Enfield (Mehmet Ali, 2001). The neighbourhood determines both the type of household and the type of schools where children will be registered. This structure creates social and cultural homogeneity which might contradict their 'multicultural' purpose and lead to the reproduction of social inequalities. So far, theoretical literature has provided contrasting results as to the extent schools encourage diversity, socio-economic mobility, and negotiation between different transnational social spaces. While Portes and Rumbaut (2001) and Berdichevsky (2008) have argued that schools promote diversity by having children from various ethnic background in certain neighbourhoods, Waters (1999), Anthias (2001, 2002), and Goulbourne et al. (2010) show that the school environment can be homogenic and static.

The school environment emphasises differences because it receives children from different ethnic backgrounds and also creates segregation by including many children from the same ethnic background. Consequently, the school system fails in different contexts at both assimilation and integration. The structure of the school system contradicts Brubaker's argument (2003: 52) that 'assimilation does not involve a shift from one homogeneous unit to another. It involves, rather, a shift from one mode of heterogeneity to another mode of heterogeneity'.

In the following sections I will explore respectively the forms of homogeneity and heterogeneity within the school environment, examining their influence on identity formation and the negotiation of transnational social spaces by TCKT youth.

\section{Forms of Homogeneity and Diversity within the School Environment}

All of my respondents grew up in London from an early age and were educated in Britain from primary school up to university. According to my respondents, homogeneity in schools is reflected in their friendship choices. Most of them, such as Cagdas, stated that classmates from the same ethnic background tend to form their own groups. This occurs more at the level of secondary schools:

All the friends I made at secondary school were from the Turkish community; we were always together and believed that we could express ourselves better. I think I was able to express myself better in Turkish and that's why I became friends with Turkish people; I had more things in common with them. It turned out that we had all immigrated to England in the early 1990's; we all speak Turkish at home, we all probably watch the same Turkish channels, we had more things in common. We became friends not because we were excluding other 
ethnic minorities but because we had more things in common (Cagdas, 23 years old, Kurdish, London School of Economics).

Cagdas explains that when he was at secondary school he felt more comfortable with classmates from the same origin because he could express himself easily, was more easily understood by people who experienced the same background, and also understood them better too. He felt part of a group by interacting with students from the same ethnic background. Cagdas also suggests that becoming a friend with people from the same ethnic background was not the result of discrimination by other ethnic minorities, but his own choice.

Similar to Cagdas, Ersin and Serpil found it more convenient to socialise with people from the same ethnic background, in order to prevent misunderstandings. These quotes show that sharing similar experiences is crucial in forming peer groups:

You are more comfortable, you understand each other. If I am with English or black friends and I tell them that I have to be at home at $6 \mathrm{pm}$, they don't understand. They think it is weird. I prefer friends for my own background because we understand each other better (Ersin, 18 years old, Kurdish, Gik-Der).

There are two or three Turkish girls in my class; I don't think I would hang out with anyone else. Not to be racist, but you get along better with people from your culture. I get along with most of them. I am glad that they are in my class. They speak my language, I can sit down and chat with them and share my feelings. They enjoy the same things, which others may not. What matters is that we speak the same language and nobody can understand us (Serpil, 18 years old, Kurdish, café in Dalston).

These interviewees all feel that they 'can understand each other better' and, therefore, feel more comfortable. This is related to mutual comprehension of culture, habits, and rules. All interviewees claimed that speaking the same language makes them closer but they also acknowledged they could also speak English. In this sense, speaking the same language signifies sharing similar life experiences which does not only include being a part of the ethnic minority group, but also covers similar experiences shared with their parents, in the local environment, and by watching transnational media. Similarities in life patterns bring these young people together in sharing their 'transnational habitats' (Guarnizo, 1997; Vertovec, 2001; Wessendorf, 2010).

Getting together with students from same ethnic background and forming groups is one way of asserting oneself in a cosmopolitan environment where young people might feel lost. It provides them a feeling of security, comfort and solidarity as was identified by Fidan:

There are no Turkish students in my class. I do not like black people but all of my classmates are black. I asked my teacher if there were any Turkish people and she said no... If there is a problem you can deal with it together; you can go out to lunch but you cannot do it with black people. I would like to attend a college where I can have Turkish friends (Fidan, 18 years old, Kurdish, café in Dalston).

Fidan's statements are even stronger: not only does she prefer to socialise with people from the same ethnic background, she 'does not like' socialising with people from different ethnic backgrounds. She does not mix with the other students from her school not even for lunch.

Forming friendships with people from the same ethnic background reduces the feeling of 'strangeness' to the school environment that some TCKT youth experience. In this sense, the impossibility of forming alliances with people from the same ethnic background is perceived as a hardship by 
Dilek:

Secondary school was hard for me. I was different from my friends. My friends were mostly British, Asian and Chinese. There was a cultural clash' (Dilek, 23 years old, Kurdish, café in Dalston).

This is a common feeling around young people from a transnational background. They have difficulties in socialising with people from different ethnic backgrounds, as they fear being discriminated against. Their lack of ability in speaking English is the most common cause for young people to socialise with people from the same ethnic background. According to Goulbourne et al. (2010: 73), 'a shared ethnic background and similar lived experiences appeared to be the most important factors shaping some of British-Italian closest friendship networks.' Similar experiences, such as mutual understanding, trust, and transnational backgrounds are also some of the reasons invoked by TCKT youth for having friends from the same ethnic background. This attitude can be also motivated in some cases by the exclusion and racism experienced at schools, as Anthias argues: 'the more the experiences of exclusion in British society, the greater the likelihood that many young people would construct themselves in ethnic terms' (2002: 492). In other words, feeling a part of a group is a way to overcome discrimination and racism in the school environment as mentioned by Azra:

I do not feel that I really fit in at school; I enjoy it, but do not feel like I fit with any of the groups. I don't think it is because of the barrier of nationality; it is just the groups are already formed in my year and it is difficult to fit in with established groups. With other classmates I get on well, my friends comprise people who are not originally British. I did not choose my friends according to their nationality, but it does seem to be the norm for 'foreigners' to stick together. I am sometimes scared that my name or background will somehow affect my prospects. If I were to encounter a racist person, say a teacher who disliked me because of my background, I would feel bad and my education would suffer - I would feel very angry if they discriminated against me (Azra, 18 years old, Turkish, house of interviewee).

Azra felt an 'outsider' in the school environment because she found it difficult to fit into any established group of students. She experienced what Back (1996) has described, in the case of Vietnamese youth in London, as a new form of racism which includes new groups who are excluded and marginalised in specific areas. This often occurs, according to Mehmet Ali (2001), through the behaviour of peers and teachers. In the case of Azra, the label of 'foreigner' leads her not only to seek support from peers of the same ethnic background but also to socialise with other ethnic minority groups. She stressed the difficulty of fitting into the majority as a result.

Forming groups with people from the same ethnic background at school is the 'easy' way to feel better or to cope with discrimination:

Racism is a misnomer since you do not have to attack another ethnic group to be a racist. You could be asserting your ethnic origin and doing nothing else. This is nationalism, but has racist implications. Although there is a lot of Pakistani, African, Turkish and Kurdish people in my school, they do not intermingle. All divided up. I cannot blame their families. It is just their way of life. They choose the easy way. They don't bother to learn about a new culture, because learning is good but it also tough. You get exposed to a new culture and things which can be challenging. They choose the easy way; they reckon they know the language and are comfortable (Nevzat, 22 years old, Kurdish, Gik-Der).

Nevzat claims that forming groups at school is related to expressing oneself to people from the same ethnic background rather than getting to know people from different backgrounds. However, 
he does acknowledge this can produce even more separatist attitudes and prejudices. For Waters, this creates a chain reaction, where people in reacting to discrimination, reproduce other forms of discrimination, as in the case of Fidan quoted above: 'the ways in which young people experience and react to racial discrimination influence the type of racial and ethnic identity they develop' (Waters, 1999: 178). As a result of experiencing discrimination and racism, TCKT youth form their own groups and experience ethnic tension and sometimes physical fights between the members of other ethnic groups at school:

I went to school in Enfield and there were always fights between African black children and Turkish Cypriot, Kurdish and Turkish children. There were clashes for no apparent reason, just because of ethnic differences (Belgin, 20 years old, Kurdish, house of interviewee).

People never admitted they fight because of ethnic discrimination. There was a tension between black people and Turkish people. I am sometimes worried to say that I am Turkish Cypriot (Tahsin, 19 years old, Turkish Cypriot, University College London).

In some cases, ethnic discrimination is also attached to communal belief and prejudice within the community, as highlighted by Ersin:

There is a lot of discrimination and prejudice at school. It is less marked than in Turkey, because of the multicultural environment. It is like our Kurdish community hates black people even though they have not met any black person. It is just based on what they see in their local community. There are a lot of educated black people as well. They hold things against other cultures. They say English people do this and that, and they are not like that. They should try to understand different cultures instead (Ersin, 18 years old, Kurdish, Gik-Der).

If forming groups with a similar ethnic background plays a crucial role in forming ethnic solidarity as the above quotes have suggested, doing so can also create differentiation too. The issue of ethnic identity becomes widely used with TCKT students differentiating them from being black. These results confirm Faas's findings where he observed that Turkish students had few cross-ethnic friendships and formed an ethnic solidarity group on the basis of a common language, culture and physical appearance, which he explained by the conflicts they have with other ethnic groups: 'Turkish youth faced substantial conflict at Millroad School and were subject to verbal and physical abuse from the African Caribbean community in their struggle for power and control of the school' (2009: 176).

Such ethnic tensions are also visible among social groups from the same country such as between Turks and Kurds. Cagdas stated that the Kurdish situation in Turkey is reflected in the everyday experiences of migrants at school:

The political debates in Turkey about Kurdish identity or the role of the current government get sort of reflected in North London. There is always tension between Turks and Kurds in Turkey, and this is reflected on the streets and in the schools of North London. These people watch Turkish television, these people do lots of things that Turkish community does. Unfortunately friends sometimes split because one is Turkish and the other is Kurdish. I have seen lots of rows, abuses and even physical fights (Cagdas, 23 years old, Kurdish, London School of Economics).

Transnational links with the country of origin through media brings political debates to the lives of young migrants. As Cagdas states, young people are also influenced by the community and family, 
even though they are not fully aware of the history and reasons for the tension between Turks and Kurds. Like Cagdas, Tulay also mentions the visible tension between Turks and Kurds at school:

There are no physical fights at university, although there is fighting between Israelis and Palestinians. There is sometimes tension between Kurdish and Turkish students. Some Kurdish students say that they are from the Kurdish community and do not wish to approach the Turkish community. When I was at secondary school, it was extremely common to have fights among Turkish Cypriots and Kurds. There were not many Turks where I grew up. There were mainly Turkish Cypriots and Kurds. During the rare occasions when they faced each other, they fought the blacks and the Kurds. The norm was to make friends from within your ethnic group. In our college there is a huge square and in one corner there are Turkish Cypriots, Kurdish, Turkish students, and in another corner Asians, in one corner Black-African students and in a smaller corner there are Chinese students. Many people form groups, which I do not think it is a good thing (Tulay, 20 years old, Kurdish, café in Stoke Newington).

For Alev, if TCKT youth used to fight with 'black children' at secondary school it was motivated by ethnic differences and prejudices; when it occurs between Kurdish and Turkish students, the fight is based on a individual and personal matters, which occur therefore less often.

There were lots of fights at my school but I cannot say that it was due to ethnic differences. It is not always between Turkish and Kurdish people. In Turkey, there are problems between Turks and Kurds but in London, Turkish and Kurdish children fight with black children; of course they sometimes fight among themselves but it is because of personal reasons. They fight with people from different ethnicities (Alev, 22 years old, Kurdish, London School of Economics).

In summary, TCKT young people seem to encounter some difficulties in interacting with different cultures. Even though most of them were born and raised in London, their home lives and communities may not equip them sufficiently to benefit from their cosmopolitan environment. According to some respondents, forming groups with similar ethnic backgrounds at secondary school was motivated by fear and discrimination which in turn creates further differentiation and discrimination. As argued by Henry (2002), the continuing existence of racism and discrimination causes the absence of transnationalism in the case of African-Caribbean people in the UK. As mentioned by the majority interviewees, the racist environment at school encourages these young people to stick to friends from their ethnic background.

Other respondents, however, highlighted the fact that forming groups with people from the same ethnic background is motivated by the feeling of understanding, security, and solidarity. In this sense, it has a positive meaning helping to improve their wellbeing and inclusion into the receiving society. This has been shown by Portes and Rumbaut (2001), who argue that socialising with people from the same ethnic background not only provides a feeling of better understanding but also impacts on academic achievement. These authors state that 'students who have kept most of their close friendship within the ethnic circle do consistently better'. According to these authors, 'full acculturation is not necessarily the best path to achievement. A selective path guided by strong family and friendship ties, yields better results on average' (Portes and Rumbaut, 2001: 242). This is corroborated by several authors who see strong ethnic ties and fluent bilingualism as a vector of success at school (Coleman, 1988; Francis and Archer, 2007; Lauglo, 2000; Modood, 2004; Zhou, 1997). This might explain why parents also encourage their children towards such behaviour.

Similar attitudes have been indentified in other ethnic communities and receiving countries. Reynolds (2006), for instance, shows that parents in the black community in the USA prefer to send their children to community based secondary schools, because they prefer them to speak their mother language well and socialise with people from the same ethnic origin. This homogeneity does not 
completely prevent them from interacting with other cultures, but does help them strengthen their transnational identity.

While some respondents tend to socialise with people only from their own ethnic background, others are more open to socialising with people from different ethnic groups. Engaging with diversity is promoted when it is the norm of the school environment. For Tahsin, socialising with different ethnic groups is also a way to 'learn' about other cultures. It can, in this sense, promote transnational experiences for young people:

The diversity of my secondary school was not a problem. The difficulty was to talk to people who were obsessed with their culture. I cannot tell why, perhaps it was easier for them, but I did not feel like finding a Turkish Cypriot group and joining them. Being with people from other cultures is better because I can learn and reflect. There were a few Turkish students at school, but I did not associate with them. I was with my Iranian, African or Japanese friends (Tahsin, 19 years old, Turkish Cypriot, University College London).

Tahsin feels comfortable with mixing different cultural repertoires in his social space and is open to every culture which helps him to understand the world better. Like Tahsin, Eylem, Tulay and Azra also stated that they enjoy the diverse environment at school:

I enjoy school. There are not a lot of Turkish students in my class. I get along with people from different countries and ethnic backgrounds (Eylem, 18 years old, Kurdish, Komkar).

It is a multicultural school and I enjoy it thoroughly. It encompasses different cultures, ethnicities, religious backgrounds, economic backgrounds. My experience at school is positive (Tulay, 20 years old, Kurdish, café in Stoke Newington).

In my class there are twenty-three people from different countries, and I like to communicate with them (Azra, 18 years old, Turkish, house of interviewee).

The respondents above are more open to understanding other cultures and communicating with them in a constructive way. The choice of mixing with other cultures depends on the environment. It is a question of what the school environment offers to young people. By learning about other cultures, interacting with young people from different ethnic background allows students to have an idea about the diversity of the society in which they live. Therefore, it opens a space for negotiation of identity among these young people and exposes them to different cultural repertoires, i.e. the culture of the receiving and sending country, and other cultures surrounding them meet within this transnational social space.

As shown above, there are two possible influences of the school environment: either homogenisation or diversity. For the young people who form homogeneous ethnic groups at school as an outcome of racism or in an attempt to increase self-confidence and security, there is a decrease in English competency. This might be related to a timing issue: forming homogenous group at secondary schools helped some interviewees to feel more secure, it becomes problematic for them later, for instance at university. In other words, though homogeneity can have a positive impact on TCKT youth's well-being and inclusion, it becomes problematic later as it can decrease bilingual skills and, therefore, represents a barrier to both inclusion and transnational experiences. The young people who prefer to interact with other cultures negotiate their identity positioning and the formation of transnational spaces earlier in their lives, and thus are less prone to these issues later on. 


\section{Language as a Vector of Inclusion and Transnationalism}

Language is a crucial factor in participating in transnational networks and for experiencing diversity in the receiving society. On the one hand, the dominance of the English language influences young migrants' ability to participate fully in transnational networks (Eckstein, 2002). On the other, being able to engage in the mother language has effects on the achievement of young people (Rumbaut, 1996). Bilingual students are able to use languages relevant to social context. For instance, they use mother language with their parents and friends from the same ethnic background, but communicate in English with their teachers and friends at school (Portes and Rumbaut, 2001). Whereas limited bilingualism causes the loss of parental language and parent-child cultural conflict, Portes and Rumbaut show that 'fluent bilinguals' not only have better relationships with both their parents and peers, but also better results at school. These results indicate that bilingualism is a driver of inclusion and transnational experiences.

The problem, as demonstrated by my interviewees, is that second generation migrants' use of English is neither grammatically correct nor sophisticated because they mainly speak Turkish in homogenous local environments where they do not mix often with other communities. Even though many of my respondents have stated that their spoken English is good, they use mainly slang and make grammatical errors, as acknowledged by Ersin:

I need to improve a lot. I would like to improve my English, especially my writing and reading skills. Many people would consider my English good because I use less slang, but I still want to improve it. I am doing my best to speak correct and fluent English (Ersin, 18 years old, Kurdish, Gik-Der).

In some cases, the accent of TCKT youths limits their acceptance. Though their spoken English may be of a high level, their accent still indicates that they are 'foreign'. Some of the respondents feel that they are singled out because of their accent, which reflects the parts of town where they live:

I am quite comfortable with English but I have always had this inferiority complex with my English level since I started university. My pronunciation is different because I am from North London. I have grown up in an environment where the way I speak is normal but it is not standard English (Tulay, 20 years old, Kurdish, café in Stoke Newington).

In the case of Tulay, speaking standard good English is important at university lectures where the majority of students speak English as a first language. However, it is less important in local areas. Many interviewees want to improve their English in order to be a part of the receiving society and to decrease the risks of discrimination based on their accent. Like Tulay, Azra states that having a 'foreign' accent makes her different from native British people.

I do not have language difficulties and I am comfortable at speaking, writing and reading English. Out of the three languages I know, English is the best, as in reading and writing skills. I have been told that when I speak, there is a slight hint of a 'foreign' accent, and I do not really like to be told that as it makes me different but not particularly in the best of ways, as accent is something that can be mocked, though that is not the case with me (Azra, 18 years old, Turkish, house of interviewee). 
Azra claims that even though she has a good level of English, her accent makes her feel different. Young people feel insecure and marginalised because of their accent which marks them as foreigners. They take a low profile in class because they fear discrimination, as highlighted by Belgin:

I am not very confident at school and find it extremely hard to approach teachers, because I do not feel comfortable. I'd rather not talk with teachers unless I have to. It is same with friends. I do not approach people; I expect them to take the first step. I think that goes back to feeling a foreigner wherever you go (Belgin, 20 years old, house of interviewee).

Young people who do not live with Turkish Cypriot, Kurdish and Turkish migrants speak English rather than Turkish in their daily lives and they have a better command of the language:

I learned English rapidly because we do not have Turkish family here; it helped. We did not live with Turkish people and had to learn English. I had a very good grasp of English in a year. I was better at school (Filiz, 21 years old, Turkish, café in Hackney).

In the case of Filiz, living with people from a different ethnic background forced her to speak English rather than Turkish. According to Min and Hong 'approximately eighty-five of Korean American second generation respondents in the US reported that they used English always or more often to communicate with their Korean friends even outside of school' (2002: 118). TCKT youth also prefer to speak in English in daily life with their Turkish peers, but they use Turkish with their parents and elder members of the community. Speaking English helps them to participate in society. According to Cressey (2006), switching from one language to another helps them to find shared meanings and symbols in a transnational social space. In this way, they preserve language and cultural competence, whilst at the same time fluent bilingualism assists them at school. The dominance of the English language influences young migrants' ability to participate fully in transnational networks (Eckstein, 2002).

Some researchers argue that strong ethnic ties accompanied by fluent bilingualism increase the achievement of young people, (Coleman, 1988; Francis and Archer, 2007; Lauglo, 2000; Modood, 2004; Portes and Rumbaut, 2001; Zhou, 1997) because it increases the likelihood of parental involvement in education (Coleman, 1988; Zhou and Bankston, 1994). According to Mehmet Ali (2001), bilingualism is related to generational, socio-economic, and educational characteristics which differ among the three social groups studied: for the second generation, the higher the socioeconomic and educational level, the higher such skills are. This is also apparent in the area of living: the richer and more heterogeneous the neighbourhood, the likely TCKT migrants are to be bilingual:

The Cypriot group includes older people who may know little English as well as the British born generations who may be fluent. The group from Turkey consists of educated professionals, who either had some knowledge of English on arrival or have attended classes, and people with little education who came from rural areas and may not see the need to learn English as they can survive without difficult in the communities (Mehmet Ali, 2001: 90).

In summary, being bilingual is important in participating in transnational social spaces because it offers the ability to participate in two spaces which bilingual young people can easily move between. 


\section{Conclusion}

The diversity of school environment has been described in the literature as a vector of inclusion of second generation migrants (Berdichevsky, 2008; Giles and Taylor, 1977; Patterson, 1969; Taylor, 1974). However, as we have seen, the reality is more complex. In general, schools receive children who live in the same neighbourhoods which in some cases decreases diversity in terms of ethnicity and socio-economic background. This homogenous organisation of schools in London questions their ability to promote socio-economic mobility, social inclusion, and transnational experiences. However, if there are children from different ethnic backgrounds at schools despite this organisation, many TCKT youths try to form homogeneous groups at secondary schools. It has been demonstrated that forming homogenous group is motivated by different things: in some cases it concerns communication, in others self-confidence and it is sometimes a reaction against discrimination and racist behaviour. This introversion might have a defensive purpose and lead to further separation and prejudice among ethnic minorities, but it also seems to reinforce, in the short term at least, TCKT youth's confidence and identity, helping them to integrate and negotiate their transnational identity more freely. In other words, when homogeneity is chosen by young people and occurs at secondary school, it seems to have some advantages in terms of inclusion and may even necessary at the beginning. However, in the medium to long term, this homogeneity prevents them from forming identities based on interaction with various cultures and, therefore, limits their ability to create transnational social spaces.

Whilst only a few interviewees stated that they enjoyed diversity at secondary school because of the opportunities to learn about other cultures and broaden their life experience, most of them recognized that diversity was valuable in their current life at university or in employment. Diversity, in this case, is not only chosen but researched by TCKT youth as a form of inclusion and maintenance of their transnational background. In order to socialise with people from different ethnic backgrounds and perform transnational interactions, TCKT youths also highlighted the need to be bilingual.

In summary, if schools have a crucial role in terms of social mobility and the inclusion of second generation migrants, it seems that their 'multicultural' policy in London is not really implemented until the university level. In fact, diversity might not be helpful in the earlier years for second generation youth, if it is not accompanied and supported by the school and social environment with measures to increase sensitivity towards racial and ethnic differences. This could include, for instance, teaching on ethnic minority history, teaching on the economic value of bilingualism, peer group discussions on ethnic issues and solutions, etc. Indeed at the secondary level, TCKT youths seem to face difficulty in knowing how to benefit from diversity. 


\section{References}

Anthias, F. (2001). 'New Hybridities, Old Concepts: The Limits of 'Culture', Ethnic and Racial Studies, 24, 4: 619-641.

Anthias, F. (2002). 'Where do I Belong? Narrating Collective Identity and Translocational Positionality', Ethnicities, 2, 4: 491-515.

Back, L. (1996). New Ethnicities and Urban Culture, London: UCL Press.

Berdichevsky, N. (2008). 'Multiculturalism in the UK: Faith Based and Ethnic Schools', New English Review, February.

Bolton, G. M. (1979). Towards a Theory of Drama in Education, London: Longman.

Brubaker, R. (2003). 'Neither Individualism or nor 'Groupism”, Ethnicities, 3, 4: 554- 557.

Coleman, J.S. (1988). 'Social Capital in the Creation of Human Capital', American Journal of Sociology, 94: 95-120.

Cressey, G. (2006). Diaspora Youth and Ancestal Homeland: British Pakistani/Kashmiri Youth Visiting Kin in Pakistan and Kashmir, Leiden: Brill.

Eckstein, S. (2002). 'On Deconstructing and Reconstructing the Meaning of Immigrant Generations'. In: Levitt, P. and Waters, M.C. (eds.) The Changing Face of Home: The Transnational Lives of the Second Generation, New York: Russel Sage.

Enneli, P., Modood, T. and Bradley, H. (2005). Young Turks and Kurds: A Set of Invisible Disadvantaged Groups, York: Joseph Rowntree Foundation.

Faas, D. (2009). 'Young Turks in England and Germany: Identity Formation and Perceptions of Europe'. In: Kucukcan, T. and Gungor, V. (eds.) Turks in Europe: Culture, Identity, Integration, Amsterdam: Turkevi Research Centre.

Francis, B. and Archer, L. (2007). Understanding Minority Ethnic Achievement, London: Routledge.

Giles, H., Bourhis, R.Y. and Taylor, D.M. (1977). Towards a Theory of Language in Ethnic Group Relations: Language, Ethnicity and Intergroup Relations, Howard Giles, London: Academic Press.

Goulbourne, H., Reynolds, T., Solomos, J. and Zontini, E. (2010). Transnational Families. Ethnicities, Identities and Social Capital, London: Routledge .

Guarnizo, L.E. (1997). 'The Emergence of a Transnational Social Formations: The Mirage of Return Migration among Dominican Transmigrants', Identities, 4: 281-322.

Henry, Z. L. (2002). 'Transnational Communities, Citizenship and African-Caribbeans in Birmingham', ESRC Transnational Communities Programme: Working Paper Series 7, www.transcomm.ox.ac.uk.

Johnston, R., Sirkeci, I., Khattab, N., Modood, T. (2010). 'Ethno-religious categories and measuring occupational attainment in relation to education in England and Wales: A multilevel analysis', Environment and Planning A, 42: 578- 591.

Kasinitz, P., Mollenkopf, J.H., Waters, M.C., Holdaway, J. (2008). Inheriting the City: The Children of Immigrants Come of Age, New York: Russell Sage Foundation.

Kivisto, P. (2003). 'Social Spaces, Transnational Immigrant Communities, and the Politics of Incorporation', Ethnicities, 3, 1: 5 -28.

Lauglo, J. (2000). 'Social Capital Trumping Class and Cultural Capital? Engagement with School among Immigrant Youth Social Capital: A Review and Critique'. In: Baron, S.; Field, J. and Schuller, T. (eds.) Social Capital: Critical Perspectives, Oxford: Oxford University Press.

Levitt, P. and Waters, M. C. (2002). Introduction. In: P.Levitt, and M.C. Waters (eds.) The Changing Face of Home: The Transnational Lives of the Second Generation, New York: Russell Sage Foundation.

Little, A. and Willey, R. (1981). Multi-Ethnic Education: The Way Forward: A Report from the Schools Council Project, Studies in the Multi-Ethnic Curriculum Project, Schools Council.

Mehmet Ali, A. (2001). Turkish Speaking Communities and Education. No Delight, London: Fatal Publications.

Min, P.G. and J. Hong (2002). 'Ethnic Attachment among Second Generation Korean Americans'. In P.G.

Min (eds.) The Second Generation: Ethnic Identity among Asian Americans, Oxford: Altamira Press.

Modood, T. (2004). 'Capitals, Ethnic Identity and Educational Qualifications', Cultural Trends, 13, 2: 87105. 
Patterson, S. (1969). Immigration and Race Relations in Britain, Institute of Race Relations: Oxford.

Portes, A. and Rumbaut, R. (2001). Legacies: The Story of the Immigrant Second Generation, Berkeley: University of California Press.

Portes, A. and Rumbaut, R. (2001a). Ethnicities: Children of Immigrants in America, Berkeley: University of California Press.

Reynolds, T. (2006). 'Caribbean Families, Social Capital and Young people's Diasporic Identities', Ethnic and Racial Studies, 29, 6: 1087-1103.

Rumbaut, G. R. (1996). 'The Crucible Within: Ethnic Identity, Self-Esteem, and Segmented Assimilation among Children of Immigrants'. In: Portes, A. (ed.) The New Second Generation, New York: Russell Sage Foundation.

Sikkink, D. and Emerson, O.M. (2008). 'School Choice and Racial Segregation in US Schools: The Role of Parents' Education', Ethnic and Racial Studies, 31, 2: 267-293.

Taylor, F. (1974). Schools and Community: A Study of Research and Literature of Education in Multi-racial Britain London: National Foundation for Educational Research.

Tomlinson, S. (1983). Ethnic Minorities in British Schools- A Review of the Literature 1960-82, London: Heinemann.

Vertovec, S. (2001). 'Transnationalism and Identity', Journal of Ethnic and Migration Studies, 27, 4: 573582 .

Waters, M. C. (1999). Black Identities: West Indian Immigrant Dreams and American Realities, Cambridge: Harvard University Press.

Wessendorf, S. (2010). 'Local Attachments and Transnational Everyday Lives: Second Generation Italians in Switzerland', Global Networks, 10, 3: 1470-226.

Zhou, M. (1997). 'Segmented Assimilation: Issues, Controversies, and Recent Research on the New Second Generation', Internal Migration Review, 31, 4: 179-191.

Zhou, M., and Bankston, C. L. (1994). 'Social Capital and the Adaptation of the Second Generation', International Migration Review, 28: 821-45.

\section{PREVIOUSLY PUBLISHED WORKING PAPERS IN THIS SERIES:}

- Ibrahim SIRKECI and Neli Esipova (2013). Turkish migration in Europe and desire to migrate to and from Turkey. Border Crossing: Transnational Working Papers, No. 1301, pp. 1-13.

- Chris Holligan and Ibrahim SIRKECI (2011). Measuring academic research performance through audit at the expense of trust: Exploring the 21st century university. Border Crossing: Transnational Working Papers, No. 1104, pp. 49-59.

- Anabel GUTIERREZ (2011). Research-teaching-practice linkages: A challenge for business schools. Border Crossing: Transnational Working Papers, No. 1103, pp. 25-48.

- Noemi SADOWSKA and Dominic LAFFY (2011). Learning uncomfortably. Border Crossing: Transnational Working Papers, No. 1102, pp. 15-24.

- Sylvia TRUMAN (2011). A generative framework for creative learning: A tool for planning creativecollaborative tasks in the classroom. Border Crossing: Transnational Working Papers, No. 1101, pp. 1-13. 